\title{
Venovenous extracorporeal membrane oxygenation-assisted tracheobronchial surgery: a retrospective analysis and literature review
}

\author{
Liang Chen", Zhexin Wang", Heng Zhao, Feng Yao \\ Department of Thoracic Surgery, Shanghai Chest Hospital, Shanghai Jiao Tong University, Shanghai, China \\ Contributions: (I) Conception and design: F Yao; (II) Administrative support: None; (III) Provision of study materials or patients: F Yao, H Zhao; \\ (IV) Collection and assembly of data: L Chen, Z Wang; (V) Data analysis and interpretation: L Chen, Z Wang, F Yao; (VI) Manuscript writing: All \\ authors; (VII) Final approval of manuscript: All authors. \\ "These authors contributed equally to this work. \\ Correspondence to: Feng Yao, MD. Department of Thoracic Surgery, Shanghai Chest Hospital, Shanghai Jiao Tong University, 241 Huaihai Road \\ West, Shanghai 200030, China. Email: yaofeng6796678@126.com.
}

Background: Airway management in tracheobronchial surgeries, especially carinal resection and reconstruction, remains one of the greatest challenges to thoracic surgeons. This study investigated the safety and effectiveness of venovenous extracorporeal membrane oxygenation (VV-ECMO) for respiratory support during tracheobronchial surgeries.

Methods: The data of patients who underwent VV-ECMO-assisted tracheobronchial surgeries at the Shanghai Chest Hospital from August 2006 to August 2021 were retrospectively reviewed. The clinicopathological, perioperative, and follow-up outcomes were analyzed.

Results: A total of 7 patients (4 males and 3 females) with a median age of 56 years (range, 11-70 years) were included in the study. The following tracheobronchial surgeries were conducted: carinal resection and reconstruction with complete pulmonary parenchyma preservation $(\mathrm{n}=4)$, left main bronchus and hemicarinal sleeve resection $(n=1)$, right upper sleeve lobectomy and hemi-carinal resection $(n=1)$, and tracheal resection and reconstruction $(n=1)$. The mean time on VV-ECMO was $167.7 \pm 65.8$ min, and the mean operative time was $192.4 \pm 55.0 \mathrm{~min}$. The average estimated blood loss was $271.4 \pm 125.4 \mathrm{~mL}$. No perioperative death or reimplantation of VV-ECMO occurred. Postoperative complications were observed in 2 patients, including 1 case of respiratory failure due to preoperative severe chronic obstructive pulmonary disease (COPD) and 1 case of chylothorax. The median hospital stay was 11 days (range, 7-46 days). The median follow-up time was 30 months (range, 21-33 months). All the patients remained alive, and no postoperative readmission occurred during the follow-up period.

Conclusions: VV-ECMO is a safe and feasible ventilation mode when intraoperative oxygen saturation cannot be well maintained during tracheobronchial surgery.

Keywords: Venovenous extracorporeal membrane oxygenation (VV-ECMO); tracheobronchial surgery; carinal resection

Submitted Aug 11, 2021. Accepted for publication Oct 22, 2021.

doi: $10.21037 /$ jtd-21-1324

View this article at: https://dx.doi.org/10.21037/jtd-21-1324

(C) Journal of Thoracic Disease. All rights reserved. 


\section{Introduction}

Airway management in tracheobronchial surgeries, especially carinal resection and reconstruction, remains one of the greatest challenges to thoracic surgeons. Mechanical ventilation, including cross-table ventilation and highfrequency jet ventilation (HFJV) through endotracheal intubation, is frequently used, but is associated with impeding operative exposure, prolonging the duration of the operation due to the repeated withdrawal of the endotracheal tube, and the risk of bronchus luminal injury (1). Extracorporeal membrane oxygenation (ECMO), which is a more invasive but effective ventilation strategy, is generally used to treat respiratory or cardiac failure, such as acute respiratory distress syndrome (ARDS), hypercapnic respiratory failure, and cardiogenic shock, among other conditions (2), or as a bridge to lung transplantation (3). ECMO is often performed with venoarterial cannulation [venoarterial ECMO (VA-ECMO)] in patients with impaired cardiac function or venovenous cannulation [venovenous ECMO (VV-ECMO)] in patients who require respiratory gas exchange support $(4,5)$. For patients with normal right ventricular function, $\mathrm{V}$-ECMO is preferred, as it avoids the need for median sternotomy, causes less heparinization than a cardiopulmonary bypass, and has a lower risk of arterial cannulation-related complications, including bleeding, ischemia, and embolism, compared with VA-ECMO (6). In addition to its application in lung transplantation, intraoperative ECMO has been shown to ensure adequate oxygenation and optimal surgical exposure, especially in situations where single-lung ventilation is insufficient to maintain oxygen saturation $(7,8)$.

This study sought to describe the use of VV-ECMO for respiratory support during tracheobronchial surgeries at our center.

We present the following article in accordance with the STROBE reporting checklist (available at https://dx.doi. org/10.21037/jtd-21-1324) (9).

\section{Methods}

\section{Patients}

The data of 495 patients who underwent tracheobronchial surgeries for lesions involving the trachea, carina, or proximal bronchus at Shanghai Chest Hospital from August 2006 to August 2021 were retrospectively reviewed. Of the 495 patients, 463 underwent cross-field intubation (93.5\%), 16 underwent $\mathrm{HFJV}$ (3.2\%), and 16 underwent ECMO (3.2\%). In total, 7 patients who underwent VV-ECMO- assisted tracheobronchial surgeries were included in this study. The study was conducted in accordance with the Declaration of Helsinki (as revised in 2013). The study was approved by ethics board of the Shanghai Chest Hospital (ethic approval No.: KS1992) and individual consent for this retrospective analysis was waived. Meticulous preoperative assessments, including cardiopulmonary evaluations, clinical staging according to radiological imaging, and bronchoscopy examinations, were conducted by expert cardiothoracic surgeons and anesthesiologists. The clinicopathological, perioperative, and follow-up results were then collected and analyzed.

\section{ECMO}

VV-ECMO cannulation was instituted by dedicated cardiologists, an ECMO team, and anesthesiologists. After the general anesthesia, the patients were placed in the supine position, and ultrasound-guided percutaneous cannulation was then established after heparinization with a single dose of heparin between 50 and $100 \mathrm{IU} / \mathrm{kg}$. One cannula was inserted into the right femoral vein for venous drainage, and the other into the right internal jugular vein (Cases 1 to 6 ) or the right subclavian vein (Case 7) for venous return. During the VV-ECMO support, mean arterial pressure, arterial blood gas level, oxygen saturation, hematocrit value, and activated clotting time (ACT) were monitored. The ACT value was assessed before starting ECMO, and the target ACT value was maintained within approximately 160-180 seconds by adjusting the dose of heparin during surgery. At the end of the operation, the VVECMO cannulas were removed, and a dose of protamine was administered to all the patients.

\section{Statistical analysis}

The continuous variables are expressed as the mean \pm standard deviation or the median (range) according to the normality of distribution. The categorical variables are expressed as the count and proportion. $\mathrm{P}$ values less than 0.05 were considered statistically significant. All the statistical analyses were performed using SPSS version 26.0 software. Photoshop version 2020 software was used to produce the images.

\section{Results}

In total, 4 male and 3 female patients underwent tracheobronchial surgeries with VV-ECMO support. The 
Table 1 The demographic characteristics of patients receiving VV-ECMO-assisted tracheobronchial surgeries

\begin{tabular}{lcccll}
\hline Case & Sex & Age (years) & Histology & Comorbidity & Indication \\
\hline 1 & Male & 70 & SCC & COPD & Difficult intubation \\
2 & Male & 56 & SCC & & Difficult intubation \\
3 & Male & 65 & SCC & LUL lobectomy 3 years prior & Carinal reconstruction with the risk of inadequate left \\
single-lung ventilation
\end{tabular}

VV-ECMO, venovenous extracorporeal membrane oxygenation; SCC, squamous cell carcinoma; COPD, chronic obstructive pulmonary disease; LUL, left upper lobe; MEC, mucoepidermoid carcinoma.

Table 2 The surgical characteristics of patients receiving VV-ECMO-assisted tracheobronchial surgeries

\begin{tabular}{|c|c|c|c|c|c|c|}
\hline Case & Procedure & Approach & Site of cannulation & $\begin{array}{c}\text { W-ECMO } \\
\text { duration (min) }\end{array}$ & $\begin{array}{l}\text { Operative } \\
\text { time (min) }\end{array}$ & $\begin{array}{l}\text { Blood loss } \\
\quad(\mathrm{mL})\end{array}$ \\
\hline 1 & Carinal resection and reconstruction & PLT, right & Femoro-jugular, right & 229 & 193 & 300 \\
\hline 2 & Carinal resection and reconstruction & PLT, right & Femoro-jugular, right & 220 & 230 & 200 \\
\hline 3 & Carinal resection and reconstruction & PLT, right & Femoro-jugular, right & 156 & 159 & 500 \\
\hline 6 & $\begin{array}{l}\text { Right upper sleeve lobectomy and } \\
\text { hemi-carinal resection }\end{array}$ & PLT, right & Femoro-jugular, right & 246 & 220 & 300 \\
\hline 7 & Tracheal resection and reconstruction & Transcervical incision & Femoro-subclavian, right & 99 & 91 & 300 \\
\hline
\end{tabular}

VV-ECMO, venovenous extracorporeal membrane oxygenation; PLT, posterolateral thoracotomy.

patients had a median age of 56 years (range, 11-70 years). Table 1 sets out the indications for establishing VVECMO in this study. Carinal resection and reconstruction with complete pulmonary parenchyma preservation was performed in the first 4 cases (Table 2). In Cases 1 and 2, VV-ECMO was used, as it was thought that it might be difficult to ensure adequate gas exchange with conventional lung isolation techniques when both the main bronchial lumina were partially occluded by the carinal neoplasm (Figure 1). Case 3, a carinal tumor patient (Figure 2), received thoracoscopic left upper lobectomy for squamous cell carcinoma at the pathologic stage of $\mathrm{T} 2 \mathrm{~N} 1 \mathrm{M} 0$ and subsequent 4 -cycle chemotherapy 3 years ago. It was thought that it might be challenging to maintain left single-lung ventilation and guarantee oxygen saturation by the residual left lower lobe. Thus, VV-ECMO was selected instead of traditional cross-field intubation to perform carinal resection and reconstruction (Figure 3). In Case 4, a neoplasm was detected in the lower trachea that was obstructing the left main bronchus and invading the carina, which was confirmed as schwannoma by biopsy. During the bronchoscopy examination, the distal end of the left main bronchus could not be reached, and the extension of the tumor could not be effectively evaluated. It was supposed that single-lung ventilation could not maintain the oxygen saturation during anastomosis once it was necessary to perform left carinal pneumonectomy eventually (Figure 4). In Case 5, conversion to VV-ECMO occurred due to intraoperative severe hypoxemia. Left main bronchus and hemi-carinal sleeve resection was 

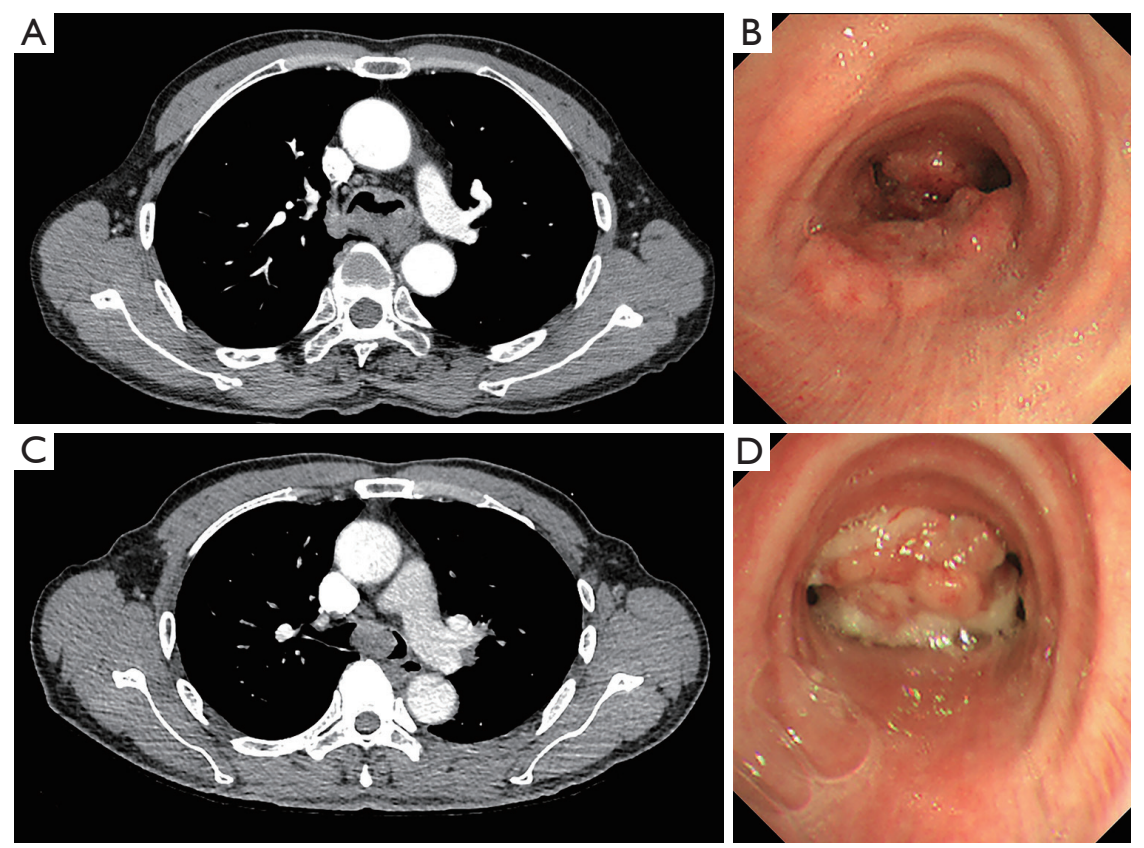

Figure 1 Preoperative computed tomography and bronchoscopy images of Case 1 (A,B) and Case 2 (C,D).

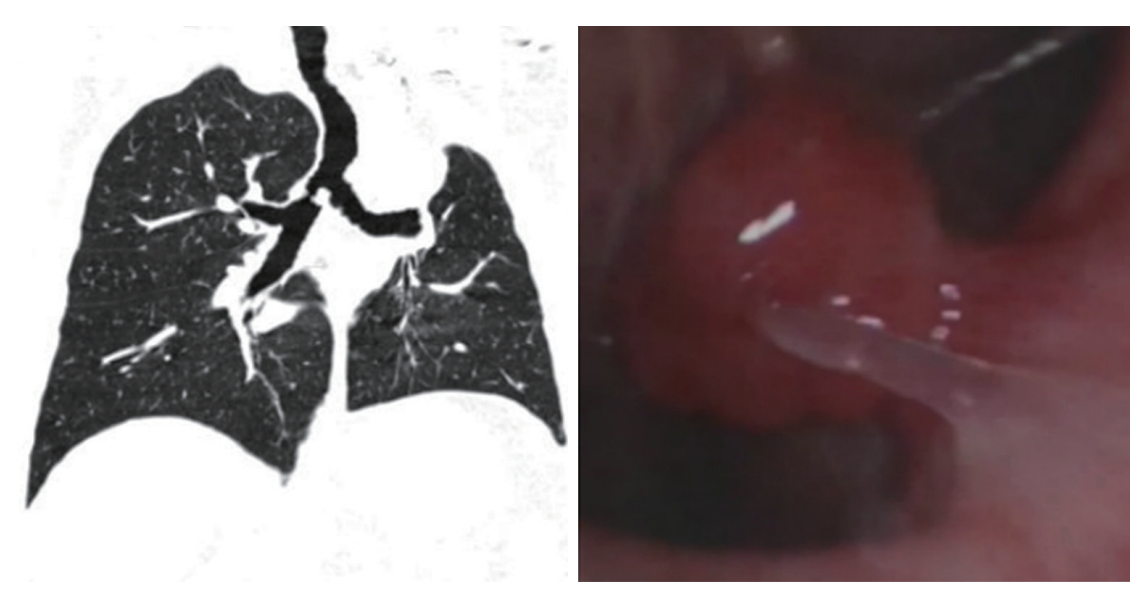

Figure 2 Preoperative computed tomography and bronchoscopy images of Case 3.

performed in an 11-year-old child with mucoepidermoid carcinoma in the left main bronchus $0.5 \mathrm{~cm}$ away from the carina (Figure 5). The oxygen saturation could not be effectively maintained by right single-lung ventilation during surgery, and no improvement was achieved after adjusting the intubation tube, sputum aspiration, or by injecting methylprednisolone. Two emergency cases received VV-ECMO in this study. Case 6, a patient with a mass in the right main bronchus, suffered from a sudden bronchial tumor rupture followed by massive hemoptysis.
In Case 7, the patient was admitted due to sudden lifethreatening hypoxemia, and the trachea was observed to be almost completely obstructed by the tumor from the computed tomography images.

All the patients were decannulated from VV-ECMO at the end of surgery and extubated in the operating room. The intraoperative VV-ECMO duration was $167.7 \pm 65.8 \mathrm{~min}$ (range, 78-246 $\mathrm{min}$ ), while the operative time was $192.4 \pm 55.0 \mathrm{~min}$ (range, 91-260 $\mathrm{min}$ ). The estimated intraoperative blood loss was $271.4 \pm 125.4 \mathrm{~mL}$, and none of 

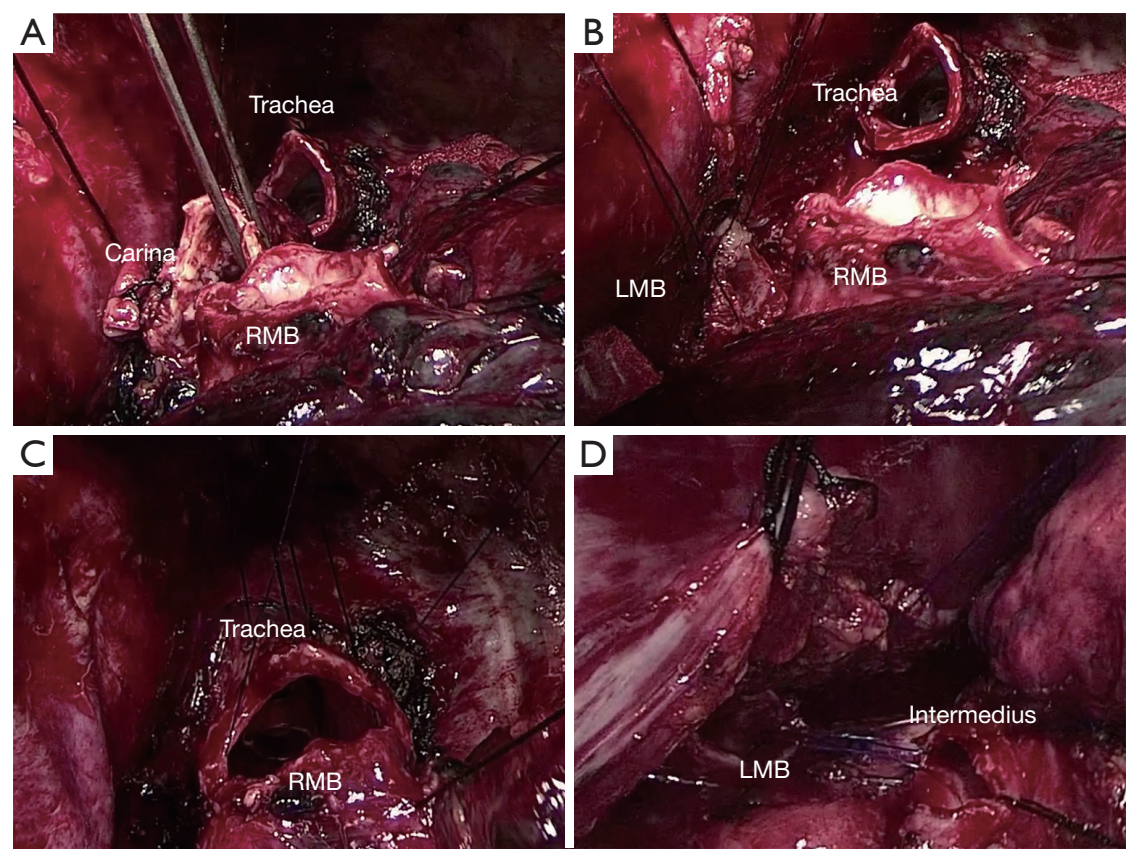

Figure 3 Carinal resection and reconstruction was performed in Case 3. (A,B) After the carina was well exposed, the trachea and the left and right main bronchus were circumferentially resected at a safe distance; (C) an end-to-end anastomosis was conducted between the trachea and the right main bronchus; (D) an end-to-side anastomosis was conducted between the left main bronchus and the right intermedius. $\mathrm{RMB}$, right main bronchus; LMB, left main bronchus.
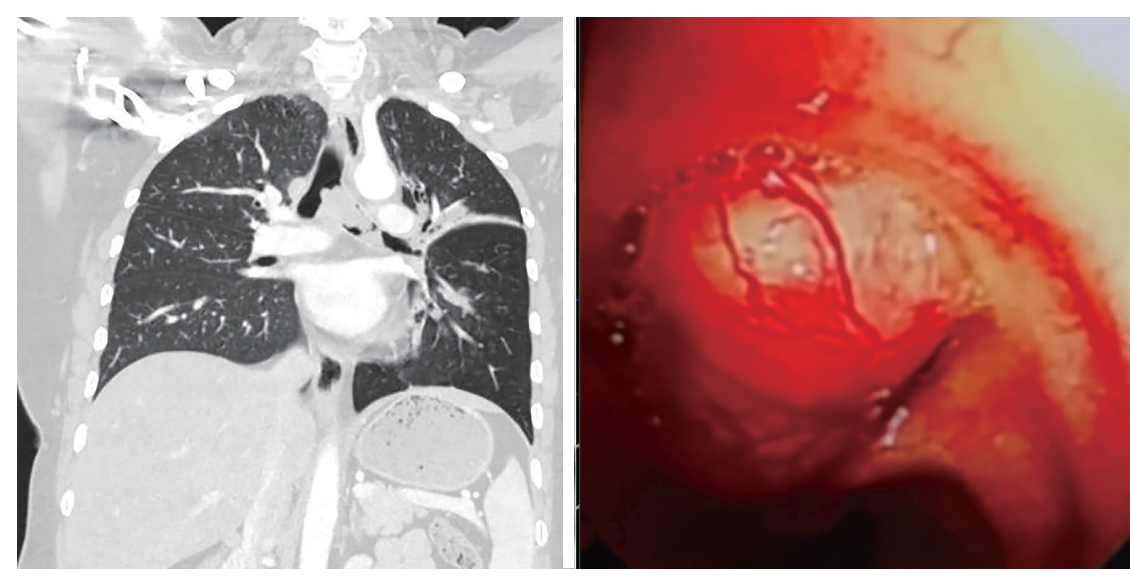

Figure 4 Preoperative computed tomography and bronchoscopy images of Case 4.

the patients received an intraoperative blood transfusion except for Case 5. No perioperative death or reimplantation of VV-ECMO occurred. Postoperative complications were observed in 2 cases (Table 3), including respiratory failure treated by mechanical ventilation in Case 1 , which was caused by preoperative severe chronic obstructive pulmonary disease (COPD), and chylothorax in Case 5. The median follow-up time was 30 months (range, 21-33 months). All the patients remained alive, and no postoperative readmission occurred during the follow-up period. 


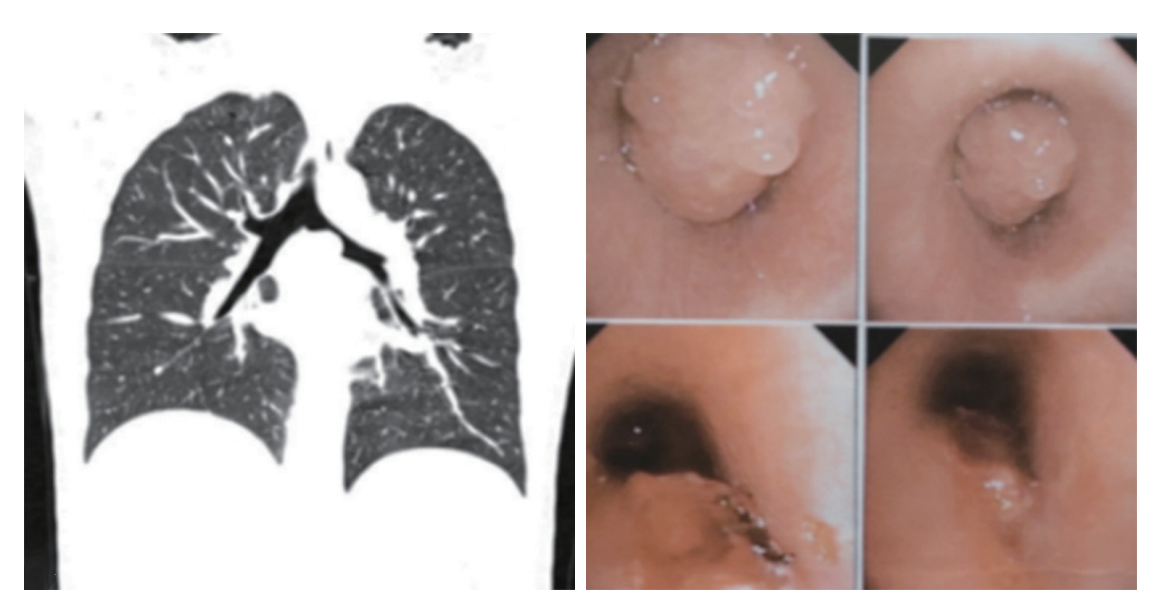

Figure 5 Preoperative computed tomography and bronchoscopy images of Case 5 .

Table 3 The postoperative course of patients receiving $\mathrm{VV}$ ECMO-assisted tracheobronchial surgeries

\begin{tabular}{lc}
\hline Variables & Overall $(\mathrm{n}=7)$ \\
\hline Mortality & 0 \\
Complications & $2(28.6 \%)$ \\
Respiratory failure & $1(14.3 \%)$ \\
Chylothorax & $1(14.3 \%)$ \\
SICU stay (days) & 5 (range, 1-28) \\
Duration of drainage (days) & 8 (range, 6-21) \\
Hospital stay (days) & 11 (range, 7-46)
\end{tabular}

VV-ECMO, venovenous extracorporeal membrane oxygenation; SICU, surgical intensive care unit.

\section{Discussion}

Airway management in tracheobronchial surgeries requires multidisciplinary discussions and individualized schemes. For bronchial resection, conventional single-lung ventilation usually guarantees adequate oxygenation by lung isolation techniques with double-lumen endotracheal intubation. For tracheal or carinal resection, single-lung ventilation by cross-field intubation is commonly applied via the insertion of an endotracheal tube into the distal trachea or one of the main bronchi during anastomosis (10). However, as surgical visualization is inevitably disturbed by the endotracheal tube, the endotracheal tube needs to be withdrawn repeatedly, which may cause intermittent apnea, increased anastomosis time, and bronchus luminal injury (11). HFJV is a sophisticated alternative with a relatively smaller diameter endotracheal tube for better surgical exposure. However, it may also cause persistent hypercapnia, lung barotrauma, pneumothorax, and mucosal injury (12). Occasionally, it may be difficult or impossible to maintain adequate intraoperative oxygenation by singlelung ventilation. As a more invasive ventilation mode, ECMO uses a bypass circuit which can provide cardiac or respiratory support without interference to the surgical field.

The use of VV-ECMO during tracheobronchial surgeries for patients with normal right ventricular function was investigated and summarized in this study. Traditionally, carinal resection and reconstruction is performed using cross-field ventilation with endotracheal intubation. It may be impossible or difficult to maintain good oxygenation by single-lung ventilation via an endotracheal tube inserted into one of the main bronchi in patients with severely obstructed main bronchi (Cases 1 and 2) (13), in patients with compromised pulmonary function due to comorbidities such as COPD, in patients who have undergone previous lung resection (Case 3) including lobectomy or pneumonectomy (14), or in patients who need to undergo extended resection such as carinal pneumonectomy (Case 4) (14). In these situations, VV-ECMO can provide oxygenation without frequent intermittent ventilation and the interruption of the atelectatic state of the operating side compared with cross-field ventilation (15). Additionally, VV-ECMO is a viable rescue therapy in emergency settings (Case 6 and Case 7) (16) or urgent situations in which conventional ventilation strategies fail (Case 5) (6). When intraoperative oxygenation cannot be well maintained by single-lung ventilation, several different scenarios should be noted 
Table 4 A literature review of the case series on ECMO-assisted tracheobronchial resection and reconstruction

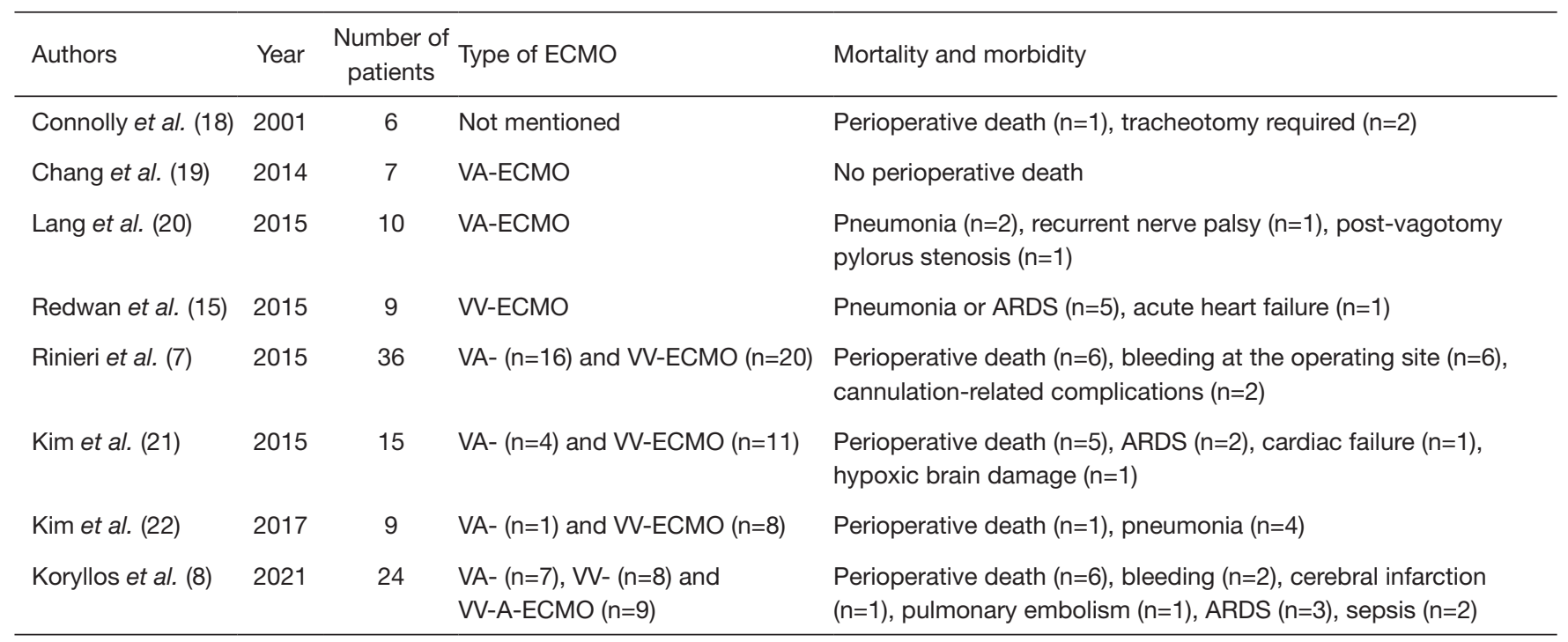

ECMO, extracorporeal membrane oxygenation; ARDS, acute respiratory distress syndrome; VA, venoarterial; VV, venovenous; VV-A, venovenous-arterial.

and addressed, including airway obstruction caused by secretion, airway spasm, anatomic variation, reduced tolerance to hypoxia, and intrapulmonary shunt, among others. Pediatric patients have much smaller airways and less cartilaginous stability, which increases chest wall compliance and metabolic requirements. Thus, pediatric patients are more vulnerable to airway compromise than adults (6). In Case 5, the pediatric patient had a history of thalassemia, which might have caused poor tolerance to hypoxia, and conventional single-lung ventilation failed to maintain the intraoperative oxygenation.

The application of ECMO in the surgical treatment of tracheobronchial injuries (17) and extended central resections has also been described (Table 4) (12,23,24). Lang et al. reviewed 10 cases of complex tracheobronchial surgeries with the assistance of VA-ECMO, and found no complications related to VA-ECMO (20). Redwan et al. reported 9 cases of pulmonary resections under VV-ECMO (15), among whom 6 patients suffered postoperative complications including pneumonia or ARDS $(\mathrm{n}=5)$ and acute heart failure $(\mathrm{n}=1)$. A multicenter retrospective study by Rinieri et al., in which 2 of 36 patients suffered cannulation-related complications, revealed that ECMO was a satisfactory alternative in complex trachea-bronchial surgery or in single-lung surgery (7). In addition, a study by Martinod et al. showed that VVECMO was well tolerated in patients requiring rigid bronchoscopy and who were at risk of respiratory failure or bleeding (25).

In general, the most common complications of ECMO are bleeding and thrombosis, including disseminated intravascular coagulation, hemolysis, fibrinolysis, cannulation and surgical site bleeding, intracranial bleeding, and gastrointestinal and pulmonary hemorrhage. Hypoxia and hypoperfusion during ECMO may also cause neurological complications, including hemorrhage, seizures, and infarction $(2,4,5,26)$. Compared to VA-ECMO, venous cannulation is less invasive, and VV-ECMO avoids the risk of arterial injury and minimizes hemodynamic disturbance $(6,13)$, which may cause thromboembolic venous disease, recirculation, and superior cava syndrome (7). However, in this study, no VV-ECMO-related complications were observed. The postoperative courses were uneventful except for 1 case of respiratory failure and 1 case of chylothorax, and no severe adverse events in the early period following discharge were observed.

\section{Conclusions}

VV-ECMO is a safe and feasible ventilation mode when single-lung ventilation cannot maintain intraoperative oxygen saturation during tracheobronchial surgery. With the assistance of VV-ECMO, tracheobronchial surgery can be reliably performed with an unobstructed surgical field and stable gas exchange maintenance. 


\section{Acknowledgments}

Funding: None.

\section{Footnote}

Reporting Checklist: The authors have completed the STROBE reporting checklist. Available at https://dx.doi. org/10.21037/jtd-21-1324

Data Sharing Statement: Available at https://dx.doi. org/10.21037/jtd-21-1324

Peer Review File: Available at https://dx.doi.org/10.21037/ jtd-21-1324

Conflicts of Interest: All authors have completed the ICMJE uniform disclosure form (available at https://dx.doi. org/10.21037/jtd-21-1324). The authors have no conflicts of interest to declare.

Ethical Statement: The authors are accountable for all aspects of the work in ensuring that questions related to the accuracy or integrity of any part of the work are appropriately investigated and resolved. The study was conducted in accordance with the Declaration of Helsinki (as revised in 2013). The study was approved by ethics board of the Shanghai Chest Hospital (ethic approval No.: KS1992) and individual consent for this retrospective analysis was waived.

Open Access Statement: This is an Open Access article distributed in accordance with the Creative Commons Attribution-NonCommercial-NoDerivs 4.0 International License (CC BY-NC-ND 4.0), which permits the noncommercial replication and distribution of the article with the strict proviso that no changes or edits are made and the original work is properly cited (including links to both the formal publication through the relevant DOI and the license). See: https://creativecommons.org/licenses/by-nc-nd/4.0/.

\section{References}

1. Lee HS, Kim HS, Shin HS, et al. Carinal Reconstruction and Sleeve Right Upper Lobectomy Assisted with Extracorporeal Membrane Oxygenator for Non-small Cell Lung Cancer - A case report -. Korean J Thorac Cardiovasc Surg 2011;44:193-6.

2. Abrams D, Combes A, Brodie D. Extracorporeal membrane oxygenation in cardiopulmonary disease in adults. J Am Coll Cardiol 2014;63:2769-78.

3. Aigner C, Wisser W, Taghavi S, et al. Institutional experience with extracorporeal membrane oxygenation in lung transplantation. Eur J Cardiothorac Surg 2007;31:468-73; discussion 473-4.

4. Gaffney AM, Wildhirt SM, Griffin MJ, et al. Extracorporeal life support. BMJ 2010;341:c5317.

5. Brodie D, Slutsky AS, Combes A. Extracorporeal Life Support for Adults With Respiratory Failure and Related Indications: A Review. JAMA 2019;322:557-68.

6. Hoetzenecker K, Klepetko W, Keshavjee S, et al. Extracorporeal support in airway surgery. J Thorac Dis 2017;9:2108-17.

7. Rinieri P, Peillon C, Bessou JP, et al. National review of use of extracorporeal membrane oxygenation as respiratory support in thoracic surgery excluding lung transplantation. Eur J Cardiothorac Surg 2015;47:87-94.

8. Koryllos A, Lopez-Pastorini A, Galetin T, et al. Use of Extracorporeal Membrane Oxygenation for Major Cardiopulmonary Resections. Thorac Cardiovasc Surg 2021;69:231-9.

9. Cuschieri S. The STROBE guidelines. Saudi J Anaesth 2019;13:S31-4.

10. Schleicher A, Groeben H. Anesthetic considerations for tracheobronchial surgery. J Thorac Dis 2020;12:6138-42.

11. Smeltz AM, Bhatia M, Arora H, et al. Anesthesia for Resection and Reconstruction of the Trachea and Carina. J Cardiothorac Vasc Anesth 2020;34:1902-13.

12. Bellier J, Sage E, Gonin F, et al. Radical Carinal Resection for a Glomic Tumor. Ann Thorac Surg 2016;102:e143-5.

13. Qiu Y, Chen Q, Wu W, et al. Extracorporeal membrane oxygenation (ECMO)-assisted intratracheal tumor resection and carina reconstruction: A safer and more effective technique for resection and reconstruction. Thorac Cancer 2019;10:1297-302.

14. Lei J, Su K, Li XF, et al. ECMO-assisted carinal resection and reconstruction after left pneumonectomy. J Cardiothorac Surg 2010;5:89.

15. Redwan B, Ziegeler S, Freermann S, et al. Intraoperative veno-venous extracorporeal lung support in thoracic surgery: a single-centre experience. Interact Cardiovasc Thorac Surg 2015;21:766-72.

16. Biancosino C, Krüger M, Kühn C, et al. First Successful Surgical Reconstruction of Bilateral Transected Main Bronchi With Extracorporeal Membrane Oxygenation Support. Ann Thorac Surg 2016;102:e135-7.

17. Korvenoja P, Pitkänen O, Berg E, et al. Veno-venous 
extracorporeal membrane oxygenation in surgery for bronchial repair. Ann Thorac Surg 2008;86:1348-9.

18. Connolly KM, McGuirt WF Jr. Elective extracorporeal membrane oxygenation: an improved perioperative technique in the treatment of tracheal obstruction. Ann Otol Rhinol Laryngol 2001;110:205-9.

19. Chang X, Zhang X, Li X, et al. Use of extracorporeal membrane oxygenation in tracheal surgery: a case series. Perfusion 2014;29:159-62.

20. Lang G, Ghanim B, Hötzenecker K, et al. Extracorporeal membrane oxygenation support for complex tracheobronchial procedures†. Eur J Cardiothorac Surg 2015;47:250-5; discussion 256.

21. Kim CW, Kim DH, Son BS, et al. The Feasibility of Extracorporeal Membrane Oxygenation in the Variant Airway Problems. Ann Thorac Cardiovasc Surg 2015;21:517-22.

Cite this article as: Chen L, Wang Z, Zhao H, Yao F. Venovenous extracorporeal membrane oxygenation-assisted tracheobronchial surgery: a retrospective analysis and literature review. J Thorac Dis 2021;13(11):6390-6398. doi: 10.21037/jtd-211324
22. Kim SH, Song S, Kim YD, et al. Outcomes of Extracorporeal Life Support During Surgery for the Critical Airway Stenosis. ASAIO J 2017;63:99-103.

23. Wannaz L, Roumy A, Letovanec I, et al. Noncircumferential membranous resection of the trachea for paraganglioma: A case report. Int J Surg Case Rep 2018;51:288-91.

24. Kuroda Y, Uchida T, Hamasaki A, et al. Treatment Strategy for Severe Airway Stenosis Due to a Thoracic Aortic Aneurysm. Ann Thorac Surg 2020;110:e195-7.

25. Martinod E, Portela AM, Uzunhan Y, et al. Elective extra corporeal membrane oxygenation for high-risk rigid bronchoscopy. Thorax 2020;75:994-7.

26. Dunkman WJ, Nicoara A, Schroder J, et al. Elective Venovenous Extracorporeal Membrane Oxygenation for Resection of Endotracheal Tumor: A Case Report. A A Case Rep 2017;9:97-100. 